\title{
Good death and bereavement in a lung cancer patient following meaning-centered couples psychotherapy by a cancer nursing specialist
}

\section{Case Report \\ Cite this article: Hayashi E, Onishi H (2021). Good death and bereavement in a lung cancer patient following meaning-centered couples psychotherapy by a cancer nursing specialist. Palliative and Supportive Care 19, 767-771. https://doi.org/10.1017/S1478951521001826}

Received: 26 May 2021

Revised: 16 September 2021

Accepted: 31 October 2021

\section{Key words:}

Good death; Grief care; Lung cancer; Meaningcentered psychotherapy (MCP); Terminal cancer

Author for correspondence: Eriko Hayashi, Nursing Course, School of Medicine, Yokohama City University, 3-9 Fukuura, Kanazawa-ku, Yokohama, Kanagawa, Japan. E-mail: erieritn@yahoo.co.jp (c) The Author(s), 2021. Published by Cambridge University Press. This is an Open Access article, distributed under the terms of the Creative Commons Attribution licence (http://creativecommons.org/licenses/by/4.0/), which permits unrestricted re-use, distribution and reproduction, provided the original article is properly cited.
Eriko Hayashi, R.N., PH.D. ${ }^{1}$ (D) and Hideki Onishi, M.D., PH.D. ${ }^{2}$ [D

${ }^{1}$ Nursing Course, School of Medicine, Yokohama City University, 3-9 Fukuura, Kanazawa-ku, Yokohama, Kanagawa 236-0004, Japan and ${ }^{2}$ Department of Psycho-oncology, Saitama Medical University International Medical Center, 1397-1 Yamane, Hidaka City, Saitama 350-1298, Japan

\begin{abstract}
Objective. There are many terminally ill cancer patients who are struggling with the meaning of life, but it cannot be said that their concerns are being adequately addressed.

Method. From a series of cancer patients undergoing end-of-life care, the case of a patient, who developed incurable lung cancer and, together with his wife, lost the meaning of life and underwent meaning-centered couples psychotherapy once every two weeks to have them consider the meaning of life together, is presented.

Results. The patient was a 70-year-old man who had been diagnosed with lung cancer and pleural dissemination 14 months earlier. The meaning-centered psychotherapy (MCP) sessions were conducted with the patient and his 70-year-old wife by a cancer nursing specialist who had received extensive training in MCP and had also received 7-year on-going supervision from a Japanese MCP-enlightened psychologist. At the same time, palliative treatment of physical distress was performed. The patient was able to discover the meaning of life as a result of MCP performed by a cancer nursing specialist for him and his spouse who had lost any notion of the meaning of life after being informed that he had terminal cancer at the time of the initial diagnosis.

Significance of results. Meaning-centered psychotherapy provided to terminal cancer patients by cancer nurses can help patients and their families express their gratitude, thereby achieving a good death for the bereaved family. Nurses are likely to increasingly perform MCP in the future.
\end{abstract}

\section{Introduction}

Steinhauser et al. (2000) listed the following aspects of a "good death": "pain relief," "one's intentions be realized," "prepare for death through the knowledge it is imminent," "ensure one has nothing left to do in one's life," and so on. In addition, it has been reported that "good relationships with family members" and "expressing gratitude to others and mental preparedness" are necessary for a good death for Japanese people (Miyashita et al., 2007). It has also been suggested that patients "telling their loved ones what they want to say" prevents family depression and complicated grief (Hebert et al., 2008).

Meaning-centered psychotherapy (MCP) is effective as a form of psychotherapy in such situations. This therapy focuses on the meaning of life and aims to improve spiritual well-being and quality of life; moreover, it is a form of intervention to clarify the meaning of the patient's life so far, the meaning of living now, and the meaning of life for the time remaining through dialogue with patients (Breitbart et al., 2018).

MCP includes meaning-centered group psychotherapy (MCGP) and individual meaningcentered psychotherapy (IMCP). IMCP, developed from MCGP by Breitbart et al., was intended to increase the flexibility of treatment implementation because scheduling, illnessrelated, or treatment location problems often hinder attendance, particularly in individuals who have advanced cancer (Breitbart et al., 2010, 2012).

Regardless of the occupation of the provider, this therapy can be performed while paying attention to the symptoms of physical distress specific to cancer patients. In general hospitals, many patients experience spiritual pain, but the number of psychologists and psychiatrists is limited. The provision of MCP by a nurse involved in cancer nursing makes it possible to deal with the spiritual distress of the patient. However, there are few reports of the involvement of nursing staff in MCP (Taylor, 1993). A case in which a nurse identified the meaning of living for a terminal cancer patient by performing MCP and facilitated the achievement of a good death for the patient and the bereaved family is presented.

\section{Case report}

The patient was a 70-year-old man. Fourteen months earlier, he was diagnosed with right upper lobe lung adenocarcinoma and pleural dissemination. 
His wife was also 70 years old, and their son was in his 30 s, and the three of them were living together. The couple had always lived together since retirement at the age of 60 years. The psychiatrist ruled out depression. The patient was eligible for MCP because he and his wife had lost the meaning of life after being informed that he had incurable cancer. The patient's physical symptoms were assessed using the Edmonton Symptom Assessment System Revised Japanese version on a numerical scale (Bruera et al., 1991; Yokomichi et al., 2015); he had low physical scores (for example, pain, nausea, lack of appetite, shortness of breath), but a high anxiety score of 7 . His life expectancy was within 6 months to 1 year. After retirement, the couple had always been together, and MCP was performed mostly as a couple. It was also done individually each time in the latter half of the process. Since we judged that Breitbart's method of IMCP was indicated, MCP was conducted for the couple once every two weeks to have them consider the meaning of life together. The therapy was conducted every two weeks because the patient's main outpatient visits for his cancer were once every two weeks.

The MCP of the case was a manualized 7-session intervention designed to assist patients with advanced cancer in sustaining or enhancing a sense of meaning, peace, and purpose in their lives as they face limitations due to the progression of disease and treatment. The seven 1-h sessions address specific sources of meaning, as well as themes related to cancer and identity, legacy, hope, and the finiteness of life. Patients are also assigned related readings and homework exercises (Table 1).

The MCP sessions were conducted by a cancer nursing specialist who had received extensive training in MCP at a graduate school before treating patients. She had also received 7-year on-going supervision from a Japanese MCP-enlightened psychologist.

\section{Session 1: concepts and sources of meaning}

At MCP in session 1, it was the first time we met. I listened and asked about his experiences and moments that felt particularly meaningful, and what he struggled to overcome.

He was told that surgery would be difficult. The patient and his wife lost the meaning of life, saying, "I don't know how to spend the rest of my life" and "Why did I get this kind of illness?"

\section{Session 2: cancer and meaning}

This intervention consisted of a review of and talk about their lives so far. In addition, he found meaning in his history of accomplishing work and providing for his spouse.

\section{Sessions 3: historical sources of meaning}

The patient found meaning in his "history", in which he had gotten a job at a big company and lived a life that did not inconvenience his wife.

\section{Session 4: attitudinal sources of meaning}

He looked back on the importance of his spouse who always spent time with him and supported him, and found the meaning of "attitude" in the feeling of connection with people.

\section{Session 5: creative sources of meaning}

He was asked to look for a calm moment when he felt peace and kindness prior to the next MCP session. He was asked about how he spent his time during the treatment, what new discoveries he had made, what kinds of situations he felt comfortable with, and the moments when he was able to be gentle. The patient found meaning in "the fulfillment of spending every day in peace while taking a walk with my spouse and feeling the changing season," "slowly eating a healthy dinner every night," "meeting the nurse with whom I am looking forward to doing MCP," and "creating" the future. During the MCP sessions, the patient seemed relaxed, smiled frequently, and was unhurried.

\section{Session 6: Experiential Sources of Meaning}

Then, he was at the stage of thinking about future "experience". As the MCP of session 6 was completed, it was decided that he had reached the stage where he could think of a good death as a couple, and it was suggested that they not be afraid to think about it. He found meaning and a positive "experience" related to living, saying, "I got cancer, but it gives more time to prepare to die compared to other illnesses."

\section{Session 7: Transitions}

He found that they had changed their minds from the first MCP to having hope in the future. "I knew that I had a limited amount of time left," "I realized the feeling and meaning of being alive," and "I know that I am ready to face such existential anguish."

\section{After all sessions}

After all seven sessions of MCP as an outpatient in the Department of Cancer Nursing, palliative assessment of physical distress was performed, and he was treated with opioids for lower back pain related to metastasis to the 12th thoracic vertebra. The couple ensured the meaning of living for the future by meeting the cancer nursing specialist, who provided them with positive support for a further 6 months, to find and express their legacy, their legacy projects, thoughts about the future, and the meaning of life.

Three days before the patient's death, he developed bloody sputum, cough, and dyspnea during home medical treatment. He underwent emergency hospitalization, and a continuous infusion of opioids was started after cancerous lymphangiopathy was diagnosed, but his dyspnea worsened. At his request, intermittent sedation with midazolam was performed, with the patient and his family understanding that "We have already talked a lot, so we have no regrets if we can't talk any further." After intermittent sedation was started, his dyspnea improved, and conversation became possible.

On waking up $5 \mathrm{~h}$ before his death, the patient thanked his wife and the medical staff, "I knew that my illness would not be cured, and I was able to meet the doctors and nurses at this hospital and find the meaning of life," "Of course, I never thought I would have such peaceful days and realized that walking and daily dinner meant living, and I regained the best of life," "Thank you very much," "It was a life without regrets," and "At the end, I had decided that I wanted to offer my gratitude and thanks, and then sleep." After that, he began to lose consciousness and later died. 
Table 1. Topics of sessions and goals of MCP

\begin{tabular}{|c|c|c|c|c|c|}
\hline & Session & Week & Intervention & Patient & Spouse \\
\hline 2 & $\begin{array}{l}\text { Cancer and Meaning: } \\
\text { Identity Before and } \\
\text { After Cancer Diagnosis }\end{array}$ & 4 & $\begin{array}{l}\text { A review of their lives so far and } \\
\text { talk about developing a general } \\
\text { understanding of their sense of } \\
\text { identity and the impact cancer } \\
\text { had on it. }\end{array}$ & $\begin{array}{l}\text { He found the meaning in his } \\
\text { "history" of accomplishing his } \\
\text { work and what he provided for } \\
\text { his spouse. }\end{array}$ & $\begin{array}{l}\text { She realized she had spent her } \\
\text { life supporting her husband } \\
\text { and she was happy about it. }\end{array}$ \\
\hline 3 & $\begin{array}{l}\text { Historical Sources of } \\
\text { Meaning: Life as a } \\
\text { Living Legacy (past, } \\
\text { present, future) }\end{array}$ & 6 & $\begin{array}{l}\text { Develop an understanding of } \\
\text { their legacy through exploration } \\
\text { of three temporal legacy modes: } \\
\text { past, present, and future. }\end{array}$ & $\begin{array}{l}\text { He found the meaning in his } \\
\text { history of working in a leading } \\
\text { company and living a life that } \\
\text { did not inconvenience his wife. }\end{array}$ & $\begin{array}{l}\text { Her husband remained a } \\
\text { gentleman and respectful } \\
\text { person. She found the } \\
\text { meaning in her "history" of } \\
\text { supporting him. }\end{array}$ \\
\hline 5 & $\begin{array}{l}\text { Creative Sources of } \\
\text { Meaning: Engaging in } \\
\text { Life via Creativity and } \\
\text { Responsibility }\end{array}$ & $12-20$ & $\begin{array}{l}\text { He was asked about how he } \\
\text { spent his time during the } \\
\text { treatment, what new discoveries } \\
\text { he had made, what kinds of } \\
\text { situations he felt comfortable } \\
\text { with, and the moments when he } \\
\text { was able to be gentle. }\end{array}$ & $\begin{array}{l}\text { Enjoying a walk with his spouse, } \\
\text { feeling the change of seasons, } \\
\text { having a healthy dinner, meeting } \\
\text { the nurse with whom he looked } \\
\text { forward to doing MCP to "create } \\
\text { the future". }\end{array}$ & $\begin{array}{l}\text { During the MCP sessions, the } \\
\text { patient seemed relaxed, smiled } \\
\text { frequently, and was unhurried. } \\
\text { She found meaning in her } \\
\text { "creating the peaceful future". }\end{array}$ \\
\hline 6 & $\begin{array}{l}\text { Experiential Sources } \\
\text { of Meaning: } \\
\text { Connecting with Life } \\
\text { via Love, Nature, and } \\
\text { Humor }\end{array}$ & 24 & $\begin{array}{l}\text { It was decided that he had } \\
\text { reached the stage where he } \\
\text { could think of a good death as a } \\
\text { couple, and it was suggested } \\
\text { that they not be afraid to think } \\
\text { about it. }\end{array}$ & $\begin{array}{l}\text { He found the meaning and a } \\
\text { positive "experience" to living, } \\
\text { saying, "I got cancer, but it gives } \\
\text { more time to prepare to die } \\
\text { compared to other illnesses." }\end{array}$ & $\begin{array}{l}\text { She found happiness from the } \\
\text { "experience" of a daily walk with } \\
\text { her spouse and having a healthy } \\
\text { dinner together every night. She } \\
\text { looked forward to meeting the } \\
\text { nurse with whom she was doing } \\
\text { MCP to "create the future. }\end{array}$ \\
\hline & $\begin{array}{l}\text { After the therapy: } \\
\text { Legacy, Hopes for the } \\
\text { future }\end{array}$ & $30-$ & $\begin{array}{l}\text { As an outpatient in the } \\
\text { Department of Cancer Nursing, } \\
\text { the palliative assessment of } \\
\text { physical distress was performed, } \\
\text { and he was treated with opioids } \\
\text { for lower back pain related to } \\
\text { metastasis to the } 12 \text { th thoracic } \\
\text { vertebra. }\end{array}$ & $\begin{array}{l}\text { He was looking forward to } \\
\text { meeting the cancer nursing } \\
\text { specialist and talking about his } \\
\text { time away. He was happy with } \\
\text { his daily walk and said his } \\
\text { goodbyes many times at dinner. }\end{array}$ & $\begin{array}{l}\text { She was happy for the } \\
\text { peaceful moment. She thought } \\
\text { she was ready to say goodbye. }\end{array}$ \\
\hline & Bereavement care & & $\begin{array}{l}\text { Bereavement care } \\
\text { Listen to bereavement family } \\
\text { story and the Legacy Project. }\end{array}$ & \multicolumn{2}{|c|}{$\begin{array}{l}\text { After his death, his wife said, "We were able to say thank you as a } \\
\text { husband and a wife just before he passed away," "I think he was happy } \\
\text { to be able to thank his doctor and nurse," "It was a satisfactory death. } \\
\text { That conversation at the end was the food of life," and "It's a strange } \\
\text { feeling to come here alone as we always came to the hospital } \\
\text { together;" it was a good death for the bereaved family. } \\
\text { The couple's legacy and thoughts for the future are experiences that } \\
\text { gave them the strength to live even when they knew they would be } \\
\text { bereaved. }\end{array}$} \\
\hline & & & & \multicolumn{2}{|c|}{$\begin{array}{l}\text { The fact that they were able to thank each other many times before } \\
\text { the bereavement gave them the strength to live; thanks to the care of } \\
\text { MCP, they were able to prepare for the bereavement } 6 \text { months before } \\
\text { his death, and his physical symptoms were controlled by the cancer } \\
\text { nursing specialist until three days before his death, allowing him to live } \\
\text { a peaceful life. Amazingly, they were able to say goodbye and thank } \\
\text { each other even } 5 \text { h before his death, which is a legacy for them. As a } \\
\text { legacy project, she was able to reflect on life, what it meant to live, and } \\
\text { even going through bereavement as a couple before death. }\end{array}$} \\
\hline
\end{tabular}


After his death, his bereaved wife said, "We were able to say thank you as a husband and wife just before he passed away," "I think he was happy to be able to thank his doctor and nurse," "It was a satisfactory death. That conversation at the end was the food of life," and "It's a strange feeling to come here alone as we always came to the hospital together"; it was a good death for the bereaved family.

\section{Discussion}

The present patient was able to discover the meaning of life as a result of MCP performed by a cancer nursing specialist for him and his spouse who had lost any notion of the meaning of life after being informed that he had terminal cancer at the time of the initial diagnosis. In the outpatient departments of general hospitals, despite patients experiencing spiritual distress as cancer progresses, medical treatment is seldom provided in association with psychologists and psychiatrists, and the distress may be untreated; however, it was suggested that it is possible to deal with the spiritual distress of patients through the participation of nurses involved in cancer nursing. In Japan, the number of psychologists and psycho-oncology practitioners engaged in treating cancer patients is insufficient, and only $5 \%$ of all hospitalized patients are examined by such practitioners at the same time (Onishi et al., 2021). Cancer nursing specialists are likely to increasingly perform MCP in the future (Komatsu, 2010; Kitajima et al., 2020).

In MCP intervention, the sources of the meaning of life can be found through the sequence of a brightly achieved "history", the "attitude" of connecting with people, "creativity" regarding the future, and the "experience" that we must have. In this sequence, the sources of meaning can be seen through "history" representing the past, "experience" the present, and "creativity" the future. It was meaningful for the bereaved wife to have a verbal farewell in the final few hours. Bereaved families who have their loved ones share goodbyes and express their gratitude before their death have significantly less depression and complicated grief (Mularski et al., 2004; Hebert et al., 2008), and it is probable that the fact that final farewells were possible in the present case also affected the level of grief experienced by the bereaved family.

As factors that allowed MCP to be realized in this case, the control of physical symptoms related to cancer was stable, hospitalization for the entire medical treatment period was short (3 days), and symptoms were well palliated up to 2 days before death. The stabilization of physical symptoms has an effect on MCP intervention and is consistent with the meaning of living in the present and the readiness to die (Breitbart et al., 2015).

In this case, $5 \mathrm{~h}$ before death, the patient himself approached the end of life by expressing his gratitude to his spouse and medical staff and being able to state what he wanted to convey, while understanding that he would soon pass away. At the end of life, it is particularly difficult to share farewells by verbal communication (Rietjens et al., 2004; van Dooren et al., 2009), but in this case, the rest achieved through intermittent sedation with midazolam is likely to have relieved the patient's physical distress.

Limitations include the following. In this case, MCP was done by a cancer nursing specialist who had received education about and supervision in MCP, but not all professional cancer nursing specialists have received such education. In order to promote the use of MCP, it is necessary to establish an appropriate educational system.

\section{Conclusion}

After all sessions of MCP as an outpatient in the Department of Cancer Nursing, the couple captured the meaning of living for the future to find and express their legacy, thoughts, and the meaning of life. In the present case, the MCP provided by the nurse allowed the patient a good death and led to less psychological distress for the bereaved family. It is expected that nurses will increasingly perform MCP in the future.

\section{Ethics}

This study received approval from the Institutional Review Board of Fujisawa Shounandai Hospital (ID: 28-004). After the patient's death, consent was obtained from the patient's family regarding the publication of this case report.

Acknowledgments. The authors would like to thank the patient and his family members. This work was supported by Grant-in-Aid for Young Scientists Number 21K17360.

Funding. The work in the writing of the report was supported by Grant-in-Aid for Young Scientists Number 21K17360. The funder did not have a role in the study design; in the collection, analysis, and interpretation of the data; and in the decision to submit the article for publication.

Conflicts of interest. The author(s) declare none.

\section{References}

Breitbart W, Rosenfeld B, Gibson C, et al. (2010) Meaning-centered group psychotherapy for patients with advanced cancer: A pilot randomized controlled trial. Psycho-Oncology 19(1), 21-28.

Breitbart W, Poppito S, Rosenfeld B, et al. (2012) Pilot randomized controlled trial of individual meaning-centered psychotherapy for patients with advanced cancer. Journal of Clinical Oncology 30(12), 1304-1309.

Breitbart W, Rosenfeld B, Pessin H, et al. (2015) Meaning-centered group psychotherapy: An effective intervention for improving psychological well-being in patients with advanced cancer. Journal of Clinical Oncology 33, 749-754.

Breitbart W, Pessin H, Rosenfeld B, et al. (2018) Individual meaningcentered psychotherapy for the treatment of psychological and existential distress: A randomized controlled trial in patients with advanced cancer. Cancer 124, 3231-3239.

Bruera E, Kuehn N, Miller MJ, et al. (1991) The Edmonton symptom assessment system (ESAS): A simple method for the assessment of palliative care patients. Journal of Palliative Care 7, 6-9.

Hebert RS, Schulz R, Copeland V, et al. (2008) What questions do family caregivers want to discuss with health care providers in order to prepare for the death of a loved one? An ethnographic study of caregivers of patients at end of life. Journal of Palliative Medicine 11, 476-483.

Kitajima M, Miyata C, Tamura K, et al. (2020) Factors associated with the job satisfaction of certified nurses and nurse specialists in cancer care in Japan: Analysis based on the basic plan to promote cancer control programs. PLoS One 15(5), e0232336.

Komatsu H (2010) Oncology certified nurse specialist in Japan. Japanese Journal of Clinical Oncology 40(9), 876-880.

Miyashita M, Sanjo M, Morita T, et al. (2007) Good death in cancer care: A nationwide quantitative study. Annals of Oncology 18, 1090-1097.

Mularski R, Curtis JR, Osborne M, et al. (2004) Agreement among family members in their assessment of the quality of dying and death. Journal of Pain and Symptom Management 28, 306-315.

Onishi H, Sato I, Uchida N, et al. (2021) High proportion of thiamine deficiency in referred cancer patients with delirium: A retrospective descriptive study. European Journal of Clinical Nutrition. doi:10.1038/s41430-021-00859-9

Rietjens JA, van der Heide A, Vrakking AM, et al. (2004) Physician reports of terminal sedation without hydration or nutrition for patients nearing death in the Netherlands. Annals of Internal Medicine 141, 178-185. 
Steinhauser KE, Clipp EC, McNeilly M, et al. (2000) In search of a good death: Observations of patients, families, and providers. Annals of Internal Medicine 132, 825-832.

Taylor EJ (1993) Factors associated with meaning in life among people with recurrent cancer. Oncology Nursing Forum 20, 1399-1405; discussion 1406-1407. van Dooren S, van Veluw HT, van Zuylen L, et al. (2009) Exploration of concerns of relatives during continuous palliative sedation of their family members with cancer. Journal of Pain and Symptom Management 38, 452-459.

Yokomichi N, Morita T, Nitto A, et al. (2015) Validation of the Japanese version of the Edmonton symptom assessment system-revised. Journal of Pain and Symptom Management 50, 718-723. 